\title{
Dexamethasone Induces Hypertrophy of Developing Medial Septum Cholinergic Neurons: Potential Role of Nerve Growth Factor
}

\author{
Bitao Shi, Stuart J. Rabin, Cinzia Brandoli, and Italo Mocchetti \\ Department of Cell Biology, Division of Neurobiology, Georgetown University, School of Medicine, Washington, DC 20007
}

\begin{abstract}
Glucocorticoid hormones influence neuronal plasticity during development; however little is known about the mechanisms of this trophic activity. Because glucocorticoids increase nerve growth factor (NGF) synthesis in selected brain areas and NGF plays a role in the development of basal forebrain cholinergic neurons, we tested the hypothesis that glucocorticoids may foster maturation of the cholinergic phenotype during postnatal development via the induction of NGF biosynthesis. The synthetic glucocorticoid dexamethasone (DEX) was injected systemically $(0.5 \mathrm{mg} / \mathrm{kg}$, s.c.) once a day for 1 week in 7 -d-old (P7) rats. DEX elicited an increase in NGF mRNA and protein levels in the cerebral cortex and hippocampus as well as specific NGF responses, such as TrkA tyrosine phosphorylation in the septum, choline acetyltransferase (ChAT) and p75 neurotrophin receptor (p75NTR) immunoreactivity, and a relative number of
\end{abstract}

cholinergic neurons in the medial septum. To examine whether the effect of DEX is age-related, we treated 1- and 14-d-old rats with DEX for 1 week. DEX increased NGF expression in rats treated from P1 to P8 but not in those treated from P14 to P21. The age-related increased expression of NGF correlated with the induction of ChAT immunoreactivity in the medial septum. Moreover, in the spinal cord, neither NGF nor ChAT levels were increased by DEX, suggesting that the glucocorticoid-mediated changes seen in the basal forebrain are associated with specific NGF responses. Our data suggest that by increasing NGF levels, glucocorticoids may play a role in the maturation of postnatal cholinergic neurons.

Key words: NGF; TrkA; ChAT; FGF2; dexamethasone; p75NTR; medial septum
Stress or other environmental stimuli may be crucial in determining neurotransmitter phenotype and neuronal morphology as well as other forms of neuronal plasticity. The discovery of mechanisms by which environmental stimuli regulate neuronal plasticity during development is important to understand physiological events underlying changes in neuronal structure and function. Recent studies have shown that corticosteroid hormones influence trophic processes in the nervous system and, in particular, play a role in the maturation of cholinergic phenotype during development. For instance, the administration of the synthetic glucocorticoid dexamethasone (DEX) in utero accelerates the maturation of cholinergic retinal neurons (Puro, 1983). Moreover, in postnatal rats DEX increases the synthesis of acetylcholine in superior cervical ganglia (Sze et al., 1993) and promotes the development of neonatal brain cholinergic nerve terminals (Zahalka et al., 1993). Although these data suggest that glucocorticoids may influence the development and maturation of cholinergic neurons during ontogeny, little is known about the mechanism(s) of these effects and the basis for a "neurotrophic" activity of glucocorticoids.

It has been reported that glucocorticoids regulate the expression of neurotrophic factors in rat brain. In particular, DEX

Received June 15, 1998; revised Aug. 3, 1998; accepted Aug. 28, 1998.

This work was supported by Research Career Development Award NS 01675 and by National Institutes of Health Grant NS 29664 to I.M. We would like to thank Drs. A. Baird and S. R. Whittemore for the generous gift of the plasmids, Dr. L. F. Reichardt for the TrkA antibody, and Drs. E. M. Johnson and V. E. Koliatsos for helpful comments.

Correspondence should be addressed to Dr. Italo Mocchetti, Department of Cell Biology, Georgetown University, School of Medicine, 3900 Reservoir Road Northwest, Washington, DC 20007.

Copyright (C) 1998 Society for Neuroscience $\quad 0270-6474 / 98 / 189326-09 \$ 05.00 / 0$ increases the synthesis of nerve growth factor (NGF) in the cerebral cortex and hippocampus of developing (Fabrazzo et al., 1991) and adult (Barbany and Persson, 1992; Saporito et al., 1994; Mocchetti et al., 1996) rats. A similar increase has been evoked by naturally occurring hormones such as corticosterone (Mocchetti et al., 1996), and alternatively, the removal of glucocorticoids by adrenalectomy decreases NGF expression in both the hippocampus and cerebral cortex (Aloe, 1989; Sun et al., 1993). The regulation of NGF biosynthesis by glucocorticoids may have physiological importance for the postnatal development of cholinergic neurons because NGF is a target-derived neurotrophic factor required for the development of cholinergic neurons of the basal forebrain (Gnahn et al., 1983; Mobley et al., 1986; Vantini et al., 1989). These neurons provide the major source of cholinergic innervation to the hippocampal formation and cerebral cortex (for review, see Butcher, 1995) and seem to play an important role in learning and memory processes (Coyle et al., 1983; Decker, 1987). Thus, given the well-established role of NGF in fostering molecular events influencing cholinergic plasticity and memory (Fisher et al., 1987), it is appealing that glucocorticoids, which seem also to regulate memory consolidation and learning (McEwen et al., 1986), by inducing NGF synthesis may help foster the development and morphological maturation of basal forebrain cholinergic neurons and affect memory processes. Should this hypothesis be true, glucocorticoids might be able to affect cholinergic development and perhaps function at an early postnatal age in which these neurons undergo intense morphological maturation (Gould et al., 1991). However, this suggestion needs to be proven. This work was undertaken to provide evidence that glucocorticoids exert an age-related trophic effect on developing cholinergic neurons of the medial septum via their ability to increase NGF synthesis. We report that DEX increases NGF 
synthesis and promotes cholinergic hypertrophy during postnatal brain development.

\section{MATERIALS AND METHODS}

Animal treatment and tissue preparation. Either gender of Sprague Dawley rats (Taconic, Germantown, NY) from postnatal day 0 (P0) to P21 were housed together with their mothers in a temperature-controlled environment with a $12 \mathrm{hr}$ light/dark cycle and food and water available ad libitum. Animals at P1, P7, or P14 received vehicle (ethanol/saline, 1:9) or DEX $(0.5 \mathrm{mg} / \mathrm{kg}$; Sigma, St. Louis, MO) subcutaneously once daily for 1 week. Body weight was monitored daily to determine potential side effects of the treatment. Rats used for biochemical determination were killed by decapitation at various time after the last daily injection. The brain and spinal cord were immediately dissected on ice (Glowinski and Iversen, 1966) and frozen on dry ice.

RNase protection assay. RNase protection assay was performed as described previously (Follesa et al., 1994; Mocchetti et al., 1996) using an 830 base ${ }^{32} \mathrm{P}$-labeled NGF RNA probe generated from EcoRI-linearized pBSrNGF (Whittemore et al., 1988) (a gift from Dr. S. R. Whittemore, University of Miami, Miami, FL). The cRNA for cyclophilin was in vitro transcribed with SP6 polymerase from EcoRI-linearized plasmid pIG15 (Follesa et al., 1994; Hayes et al., 1995) and was used as a standard control to monitor artifacts caused by extraction of RNA. The plasmid RObFGF103 (a gift from Dr. A. Baird, The Whittier Institute, La Jolla, CA), containing a 1016 base portion of the rat basic fibroblast growth factor (FGF2) cDNA (Shimasaki et al., 1988), was linearized with NcoI and used as a template for the in vitro transcription assay with T7 RNA polymerase as described previously (Follesa et al., 1994).

Hybridization with total RNA was performed at $50^{\circ} \mathrm{C}$ overnight. RNA was digested with RNase A $(1 \mathrm{U} / \mathrm{ml})$ and $\mathrm{T} 1(200 \mathrm{U} / \mathrm{ml})$ for $30 \mathrm{~min}$ at $37^{\circ} \mathrm{C}$. The reaction was stopped, and the pellet containing the RNARNA hybrid was dissolved in loading buffer, boiled at $95^{\circ} \mathrm{C}$, and separated on a $5 \%$ polyacrylamide/urea sequencing gel. NGF and FGF2 mRNA protected fragments were visualized by autoradiography on x-ray film using the Chronex Quanta III intensifying screen. The content of trophic factor mRNA was calculated by measuring the peak densitometry area of the autoradiograph analyzed with a laser densitometer (Hoefer GS 300 scanning densitometer) normalized by the peak densitometry area of the cyclophilin autoradiograph band as described previously (Follesa et al., 1994; Mocchetti et al., 1996).

NGF two-site enzyme immunoassay. The quantitative two-site enzyme immunoassay for the determination of NGF, described by Korsching and Thoenen (1985), was performed with the modifications described in our publications (Fabrazzo et al., 1991; Hayes et al., 1995) in which an immunoassay system from Promega (Madison, WI) was used. In brief, brain tissues from P14 or P21 rats were sonicated in 30 vol of homogenization buffer [100 mm Tris-HCl, $1 \mathrm{M} \mathrm{NaCl}$, 2\% BSA, 4 mм EDTA, 2\% Triton X-100, $0.02 \%$ sodium azide, and the following protease inhibitors (Sigma): $0.1 \mu \mathrm{g} / \mathrm{ml}$ pepstatin A, $5 \mu \mathrm{g} / \mathrm{ml}$ aprotinin, $0.5 \mu \mathrm{g} / \mathrm{ml}$ antipain, $167 \mu \mathrm{g} / \mathrm{ml}$ benzamidine, and $5.2 \mu \mathrm{g} / \mathrm{ml}$ PMFS]. Homogenates were then centrifuged at $13,000 \times g$ for $15 \mathrm{~min}$, and supernatants were assayed for NGF by an NGF-specific enzyme-linked immunoabsorbant assay (Promega) using 96-well vinyl round plates (Nunc Maxisorp plates, Naperville, IL) precoated with anti-NGF antibody following the protocol recommended by the manufacturer. Total protein content was measured from aliquots of the same supernatant by the Bradford Coomassie blue colorimetric assay (Bio-Rad, Hercules, CA). Absorbance for each sample was normalized to a standard curve (ranging from 0 to $500 \mathrm{pg} / \mathrm{ml}$ of NGF) and expressed as picograms of NGF per milligram of protein.

TrkA tyrosine phosphorylation. TrkA tyrosine phosphorylation was performed as described (Rabin and Mocchetti, 1995). In brief, tissues from brain areas were lysed in $1 \mathrm{ml}$ of lysis buffer (1\% Nonidet P-40, 20 mu Tris, pH 8.0, 137 mu NaCl, 10\% glycerol, 1 mm phenylmethylsulfonyl fluoride, $0.15 \mathrm{U} / \mathrm{ml}$ aprotinin, $20 \mu \mathrm{M}$ leupeptin, and $1 \mathrm{~mm}$ sodium vanadate) at $4^{\circ} \mathrm{C}$. After removal of cellular debris by centrifugation, protein levels in the lysates were measured by the Bradford Coomassie blue colorimetric assay (Bio-Rad). Proteins in each sample were equalized and incubated with TrkA-specific antibody (a gift from Dr. L. F. Reichardt) (Clary et al., 1994) followed by protein A sepharose precipitation (Pharmacia, Piscataway, NJ) at $4^{\circ} \mathrm{C}$ for $2 \mathrm{hr}$ as described previously (Rabin and Mocchetti, 1995), and then the precipitate was washed with NP-40 lysis buffer and water before resuspension in $10 \mu \mathrm{l}$ of sample buffer (2\% SDS, $100 \mathrm{~mm}$ dithiothreitol, $10 \%$ glycerol, and $0.25 \%$ bromophenol blue) for electrophoresis on a $7.5 \%$ SDS PAGE gel. Gels were transferred to nitrocellulose and probed overnight at $4^{\circ} \mathrm{C}$ with anti- phosphotyrosine (anti-ptyr) monoclonal antibody 4G10 (Upstate Biotechnology, Lake Placid, NY) diluted with Tris-buffered saline with a final concentration of $0.2 \%$ Tween 20 . Blots were analyzed by use of an ECL system (Amersham, Arlington Heights, IL).

Immunohistochemistry. Animals used for immunohistochemistry studies were anesthetized with chloral hydrate $(350 \mathrm{mg} / \mathrm{kg}) 8 \mathrm{hr}$ after the last injection and transcardially perfused with $4 \%$ paraformaldehyde in $0.1 \mathrm{M}$ phosphate buffer, $\mathrm{pH}$ 7.4. Brains and spinal cords were removed, postfixed in the same solution at $4^{\circ} \mathrm{C}$ overnight, transferred to 10,20 , and $30 \%$ sucrose solutions, and then frozen on dry ice. All tissues were stored at $-70^{\circ} \mathrm{C}$ until processed. Serial $30 \mu \mathrm{m}$ cross-sections prepared from groups of rats that received different treatments were blocked together to allow comparison of identically processed tissue.

Sections from the medial septum and spinal cord were processed for choline acetyltransferase (ChAT) and p75 neurotrophin receptor (p75NTR) immunohistochemistry essentially as described previously (Sobreviela et al., 1994). In brief, floating sections were treated in Tris- $\mathrm{HCl}$ solution, $\mathrm{pH} 7.4$, containing $0.3 \%$ hydrogen peroxide to inhibit endogenous peroxidase activity and then were soaked at room temperature for $1 \mathrm{hr}$ in blocking solution containing 40 drops $/ 10 \mathrm{ml}$ of Avidin D, $2 \%$ bovine serum albumin (BSA), $0.3 \%$ Triton X-100, and $10 \%$ normal horse serum. Sections were incubated overnight at $4^{\circ} \mathrm{C}$ in a solution containing biotin, $1 \%$ BSA, $0.4 \%$ Triton $\mathrm{X}-100,2 \%$ normal horse serum, and monoclonal mouse anti-ChAT (1:60; Boehringer Mannheim, Indianapolis, IN) or monoclonal mouse anti-p75NTR (1:4000; Oncogene Science, Cambridge, MA). Sections were then incubated in a solution containing biotinylated secondary antibody (rat-adsorbed horse antimouse IgG; 1:200; Vector Laboratories, Burlingame, CA) at room temperature for $1 \mathrm{hr}$. Sections were incubated in avidin-biotin-peroxidase solution (ABC Elite kit, Vector Laboratories), and ChAT or p75NTR was visualized by the use of nickel-intensified diaminobenzidine (DAB). Sections were mounted on gelatin-coated slides and coverslipped with DPX mountant (BDH Chemicals, Poole, UK). Sections from experimental groups were stained simultaneously with corresponding vehicle groups to exclude staining differences and with negative control sections processed with the omission of the primary antibody.

Quantitation of morphological characteristics and statistical analysis. The medial septum was analyzed in its entirety by sectioning the brain from the appearance of the genu of the corpus callosum to the decussation of the anterior commissure (rostrocaudal distance, $\sim 1000 \mu \mathrm{m}$ ). Every fourth section in six series through this area was processed for ChAT immunoreactivity; adjacent sections were processed for P75NTR immunoreactivity. Quantitation of the septal cholinergic neurons was obtained by an image analysis program (Image-Pro Plus; Media Cybernetics, Silver Spring, MD). Images were captured using a $20 \times$ objective lens via a CCD color video camera (Model Kp-D 50u; Hitachi, Tokyo, Japan) attached to a Zeiss microscope. The procedure for cell counts, size, and immunoreactive intensity of ChAT neurons was performed essentially as described by previous reports (Sofroniew et al., 1993; Teng et al., 1998). ChATimmunoreactive neurons considered for counting were confined to the following ranges: optical intensity, 0 darkest to 180 background; area, $50-1500 \mu \mathrm{m}^{2}$; maximum diameter, $80-150 \mu \mathrm{m}$; average diameter, $30-80$ $\mu \mathrm{m}$; and minimum diameter, $4-30 \mu \mathrm{m}$. In addition, a manual procedure of analysis was performed to eliminate large elongated fibers and to correct background differences during staining and image capturing. Edit menu was used to split a single object manually (usually a cluster that Image-Pro has counted as one object) into two or more objects. To reduce the variability of the immunohistochemical staining determination of cell counts, cell size, and optical density, the analysis was taken from both sides of the medial septum in each section. The number of immunoreactive neurons was derived by taking into account the counted profile, section thickness, and longest cell diameter (Abercrombie, 1946) and was then expressed as an average per section. Values for cell size were expressed as mean area per neuron per section. Values for cell diameter were expressed as average micrometers per neuron per section. Optical immunostaining intensity, obtained after subtracting background, was expressed as mean density on the gray scale per neuron per section and represented the average per neuron per section from all sections for each animal. A total of 40 sections per group was analyzed.

\section{RESULTS}

\section{DEX increases NGF mRNA levels}

We have shown previously that a single systemic administration of DEX increases NGF synthesis in selected brain areas of 
A

Figure 1. DEX increases NGF and FGF2 mRNA in the rat brain. Rats (1-, 7-, and 14-d-old) received vehicle or DEX $(0.5 \mathrm{mg} / \mathrm{kg}$, s.c.) once daily for $7 \mathrm{~d}$ and were killed $6 \mathrm{hr}$ after the last injection. $A$, Representative autoradiogram shows an increase in the NGF and FGF2 mRNA protected fragments (arrowheads) in the cerebral cortex of a P8 DEX-treated rat (lanes 4-6) compared with that of control rats (lanes 1-3). DEX failed to change the levels of cyclophilin mRNA $(C Y C) . B, C$, The content of NGF mRNA $(B)$ and FGF2 mRNA $(C)$ was determined in the indicated brain regions as described in Materials and Methods. Data, expressed as percent of control, are the mean \pm SEM of three separate experiments with at least three animals per group in each experiment ( $n=13$ per group). ${ }^{*} p<0.05$, and $* * p<0.01$ versus control (ANOVA and Dunnett's test).

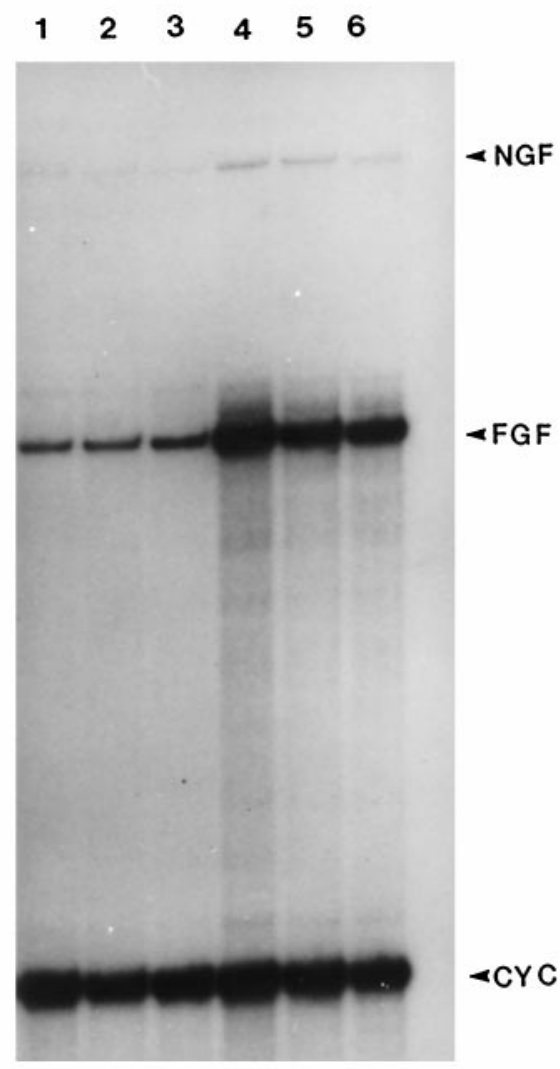

B

Z8 days old $\left.\begin{array}{l}450 \\ 400\end{array}\right] \quad$ NGF mRNA 14 days old

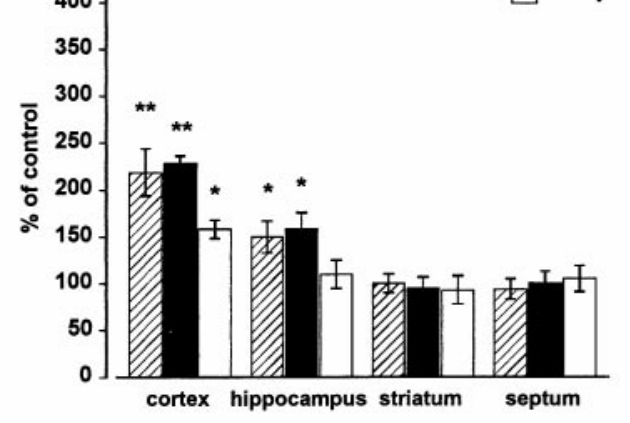

C

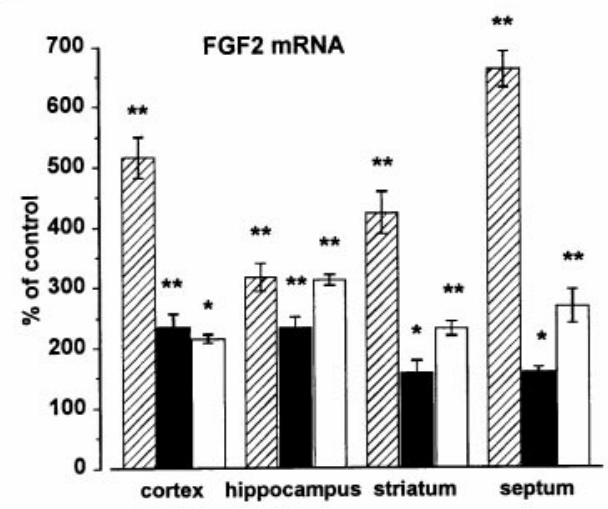

postnatal developing rats (Fabrazzo et al., 1991; Colangelo et al., 1998). We examined whether a subchronic treatment of DEX leads to a prolonged increase in NGF synthesis in the rat brain. Vehicle control or DEX $(0.5 \mathrm{mg} / \mathrm{kg}$, s.c) was injected daily in 1-, 7-, and 14-d-old rats for $7 \mathrm{~d}$. Rats were killed $6 \mathrm{hr}$ after the last injection, and NGF mRNA levels were determined by RNase protection assay (Fig. $1 A$ ). In animals treated from $\mathrm{P} 1$ to $\mathrm{P} 8$ (8-d-old) and those from P7 to P14 (14-d-old), DEX elicited a 2and 1.5-fold increase in the level of NGF mRNA in the cerebral cortex and hippocampus, respectively (Fig. $1 B$ ). No changes were observed in NGF mRNA levels in the striatum, septum (Fig. 1B), or cerebellum (data not shown) in both animal groups, indicating that the effect of DEX was brain area specific. Moreover, a lower dose of DEX $(0.05 \mathrm{mg} / \mathrm{kg}$, s.c.) for $7 \mathrm{~d}$ failed to change NGF mRNA in the cortex and hippocampus in both experimental groups (data not shown). In animals treated with DEX from P14 to P21 (21-d-old), DEX increased NGF mRNA in the cerebral cortex only (Fig. $1 B$ ), and this effect was weaker than that observed in $\mathrm{P} 8$ and $\mathrm{P} 14$ rats.

\section{DEX increases FGF2 mRNA levels}

DEX elicited a weak increase in NGF mRNA levels in 21-d-old rats (Fig. $1 B$ ), suggesting that DEX may be poorly distributed in the brain. Because glucocorticoids increase the expression of FGF2 in the brain of developing, adult, and aged rats (Mocchetti et al., 1996; Colangelo et al., 1998), we measured FGF2 mRNA levels as a control for any experimental artifacts and to confirm or eliminate the regional-specific induction of NGF by DEX. RNase protection assay of total RNA from the same tissue samples used to determine NGF mRNA (Fig. $1 A$ ) revealed that DEX increases FGF2 mRNA levels in P8 rats in all areas examined (Fig. 1C), confirming the differential induction of FGF2 and NGF by DEX. In addition, because DEX elicited a weaker effect on NGF mRNA levels in P21 rats, RNase protection analysis with FGF2 cRNA was performed also in P14 and P21 rats. In both groups DEX increased FGF2 mRNA to a similar extent (Fig. 1C), suggesting that the weak effect of DEX on NGF in 21-d-old rats is not attributable to the altered ability of DEX to bind to glucocorticoid receptors or to its poor distribution in the brain.

\section{DEX increases the levels of NGF proteins}

The DEX-mediated increase in NGF mRNA expression may have a pharmacological relevance if it is followed by an accumulation in NGF protein levels. To investigate whether DEX also increases NGF protein in the cerebral cortex and hippocampus, we gave $\mathrm{P} 7$ and $\mathrm{P} 14$ rats vehicle or $\operatorname{DEX}(0.5 \mathrm{mg} / \mathrm{kg}$, s.c. $)$ for 1 week and killed the rats $8 \mathrm{hr}$ after the last injection. A two-site immunoassay revealed that DEX increased NGF proteins in both the hippocampus and cerebral cortex of P14 rats (Fig. 2). Because in these animals DEX also increases NGF mRNA, it appears that in P14 rats DEX enhances NGF synthesis. In 21-d-old rats the glucocorticoid failed to elicit a significant increase in NGF protein levels (Fig. 2), which is consistent with the weak induction of NGF mRNA levels. Thus, in P21 rats DEX does not appear to induce NGF synthesis. Future studies aimed at examining whether DEX alters NGF metabolism will confirm this suggestion.

\section{DEX increases ChAT immunoreactivity}

The ability of DEX to increase NGF synthesis prompted us to examine whether DEX may have a trophic effect on cholinergic neurons. P7 rats received a systemic injection of DEX $(0.5 \mathrm{mg} / \mathrm{kg}$, s.c.) daily for $7 \mathrm{~d}$ and were killed $8 \mathrm{hr}$ after the last injection. 


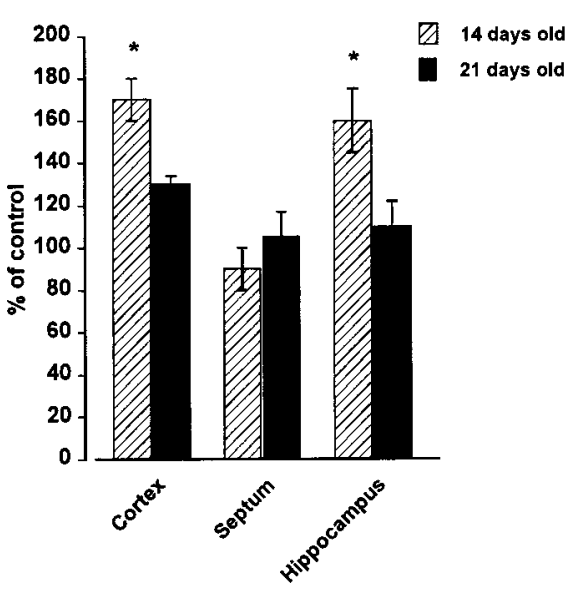

Figure 2. DEX increases NGF protein levels. Seven- and fourteen-dayold rats received vehicle or DEX $(0.5 \mathrm{mg} / \mathrm{kg}$, s.c. $)$ daily for $7 \mathrm{~d}$ and were killed $8 \mathrm{hr}$ after the last injection. NGF protein content was determined by a two-site immunoassay in the indicated brain areas. NGF levels in the cerebral cortex and hippocampus of control 14-d-old rats were $59.10 \pm$ 10.32 and $84.00 \pm 9.28 \mathrm{pg} / \mathrm{mg}$ of protein, respectively. Data, expressed as percent of control, are the mean \pm SEM of five independent samples for each group. ${ }^{*} p<0.01$ (ANOVA and Fisher's test).

Cholinergic neurons of the medial septum were identified by immunohistochemical analysis using a ChAT antibody. In control rats, an appreciable number of cells showed a moderate ChAT immunostaining (Fig. $3 A, C$ ), similar to that in an earlier report (Gould et al., 1991). Interestingly, the intensity of ChAT immunoreactivity (Fig. $3 B, D$ ) was increased in DEX-treated rats when compared with controls. Image analysis of ChAT-positive neurons revealed that DEX increased the relative levels of immunoreactivity as well as the number of ChAT-positive neurons (Fig. $3 E)$. In rats receiving a lower dose of DEX $(0.05 \mathrm{mg} / \mathrm{kg}$, s.c. $)$ for 1 week, which failed to change NGF expression, we did not observe any changes in the cholinergic indices mentioned above (Fig. $3 E$ ), nor were changes found in rats receiving a single acute injection of DEX and killed 1 week after the injection (Fig. $3 E$ ).

\section{The DEX-mediated increase in ChAT immunoreactivity} is age-dependent

To correlate the ability of DEX to increase ChAT immunoreactivity with its effect on NGF synthesis, we have examined the efficacy of DEX on cholinergic parameters in the other two age groups of rats (P8 and P21) in which DEX elicits a strong and weak increase in NGF mRNA, respectively (see Fig. $1 A$ ). Oneand fourteen-d-old rats received DEX $(0.5 \mathrm{mg} / \mathrm{kg})$ for $7 \mathrm{~d}$ and were killed $8 \mathrm{hr}$ after the last injection. In animals receiving this glucocorticoid from P1 to P8, DEX increased the immunoreactivity and size of ChAT-positive neurons (Fig. 4). Instead, no changes in cholinergic parameters were seen in P21 rats (Fig. 4) in which DEX failed to elicit a significant increase in NGF protein levels (Fig. 2). These data suggest that DEX can induce a selected hypertrophy of cholinergic neurons depending on the amount of NGF produced and the stages of postnatal development.

\section{The DEX-induced FGF2 does not regulate cholinergic neuron maturation}

FGF2 has been shown to exert trophic activity on injured cholinergic neurons in vivo (Anderson et al., 1988; Fagan et al., 1997a). Because DEX, in addition to NGF, induces also FGF2 mRNA, FGF2 may participate in the DEX-mediated hypertrophy of developing cholinergic neurons observed in this study. FGF2 was infused intraventricularly $(6 \mu \mathrm{g} / 10 \mu \mathrm{l})$ into P7 rats for 1 week. Image analysis of ChAT-immunoreactive neurons in the medial septum revealed that there were no significant morphological changes in cholinergic neurons in either density, number, diameter, or size (Fig. 5). These data suggest that the DEX-mediated increase in ChAT immunoreactivity most likely is caused by its ability to increase NGF.

\section{DEX increases TrkA tyrosine phosphorylation}

The DEX-mediated increase in ChAT levels could be caused by a direct effect of DEX on ChAT expression and not by its ability to increase NGF. Therefore, we examined another parameter of NGF activity. It has been established that NGF binding to TrkA receptor evokes a highly specific, rapid, and easily measurable receptor autophosphorylation (Kaplan et al., 1991). Thus, TrkA phosphorylation can be a useful response to estimate the "downstream" biological effectiveness of NGF. Seven-day-old rats received DEX $(0.5 \mathrm{mg} / \mathrm{kg}$, s.c. $)$ either acutely or chronically for $7 \mathrm{~d}$ and were killed at 6,15 , and $24 \mathrm{hr}$ after the last injection. Lysates from the hippocampus and the septum of control and DEXtreated rats were prepared (Rabin and Mocchetti, 1995) and precipitated with a TrkA-specific antibody (Clary et al., 1994) before protein blotting and were analyzed by Western blot with phosphotyrosine antibody. A single injection of DEX (rats killed 6,15 , and $24 \mathrm{hr}$ later) failed to increase TrkA tyrosine phosphorylation at any time in the septum (Fig. $6 A, C$ ) or in the hippocampus (data not shown). In contrast, in the septum of DEX chronically treated rats, we observed an increase in TrkA tyrosine phosphorylation at $6 \mathrm{hr}$ (Fig. $6 C$ ). The peak of effect was reached at $15 \mathrm{hr}$ (Fig. 6A,C). By $24 \mathrm{hr}$, TrkA tyrosine phosphorylation, although declining toward control levels, was still significantly higher than that observed in control rats (Fig. 6C). Importantly, we observed an increase in tyrosine phosphorylation of other phosphotyrosine bands (e.g., bands below $110 \mathrm{kDa}$ ) in $\mathrm{DEX}$ treated rats. Because these bands most likely represent association of tyrosine-phosphorylated TrkA target proteins (Kaplan et al., 1991; Hempstead et al., 1992), these data support the hypothesis that DEX, by activating TrkA receptors, enhances TrkA signaling. No changes in TrkA tyrosine phosphorylation were observed in the hippocampus of these animals (data not shown). Stripping and reprobing the blots with pan-trk antibody revealed no changes in Trk levels at any time (Fig. 6B). In addition, analysis of TrkA immunoreactivity of the septal area revealed no changes in TrkA levels (data not shown), suggesting that DEX increases TrkA activity without affecting the basal expression of TrkA.

\section{DEX increases p75NTR immunoreactivity}

The low-affinity receptor p75NTR colocalizes with TrkA in the basal forebrain cholinergic neurons (Sobreviela et al., 1994). In addition, expression of p75NTR has been shown to be increased by NGF (Meakin et al., 1992; Colangelo et al., 1994). Therefore, we have examined whether a prolonged treatment (7 d) with DEX in 14-d-old rats can upregulate p75NTR levels. When compared with that in control rats (Fig. $7 A, C$ ), p75NTR immunoreactivity in both cell bodies and fibers in DEX-treated rats was more intense (Fig. 7B,D). Moreover, image analysis of p75NTR immunoreactivity confirmed that DEX increased p75NTR levels (Fig. 7E). 

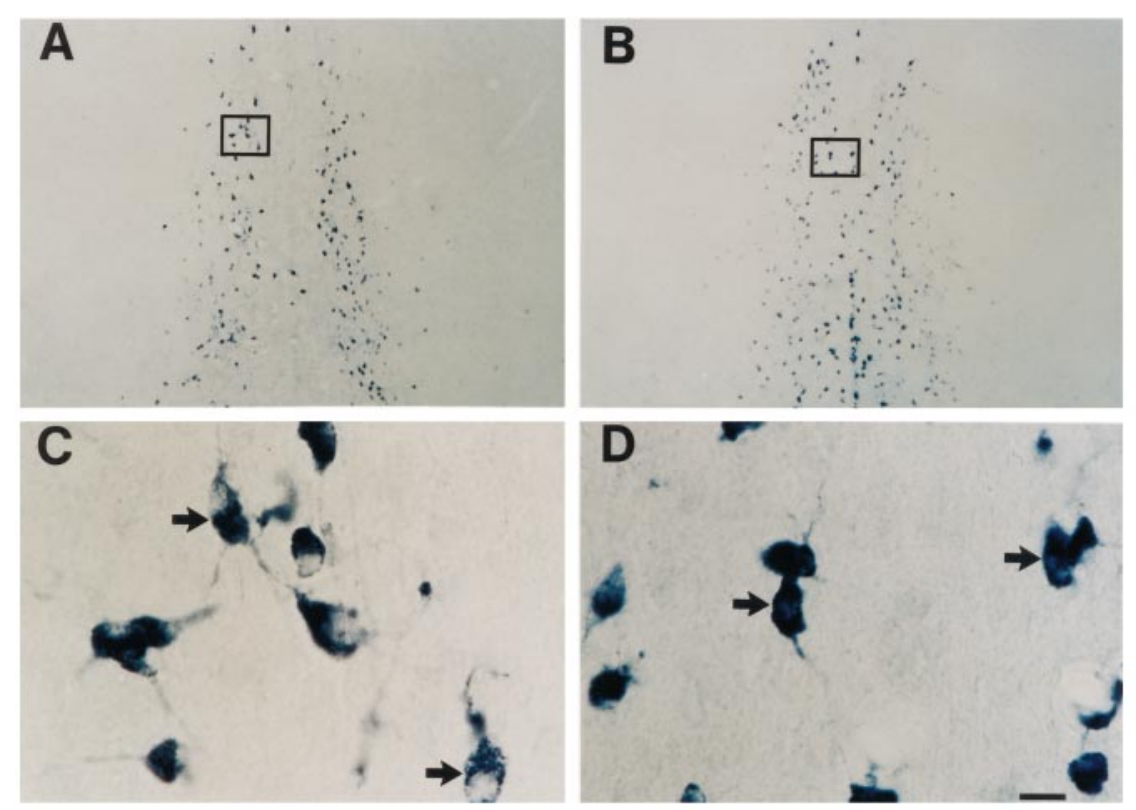

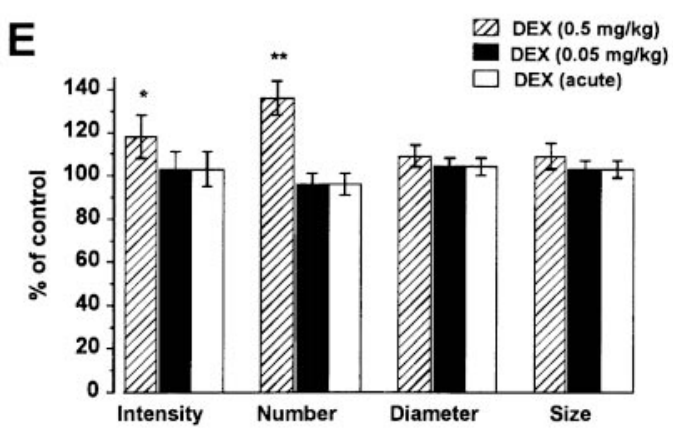

Figure 3. Effect of DEX on ChAT-immunoreactive neurons in the medial septum. $A-D$, Brain sections through the medial septum of P14 rats treated with vehicle $(A, C)$ or DEX $(B, D)$ and analyzed by ChAT immunohistochemistry. $C$ and $D$ are higher magnifications of the regions designated by the squares in $A$ and $B$, respectively. Arrows in $D$ show more ChAT immunoreactivity compared with control $(C$, arrows). Scale bars: $A, B, 250 \mu$ m; $C, D$, $20 \mu \mathrm{m}$. $E$, The image analysis of the intensity of ChAT immunoreactivity and the number, diameter, and size of ChAT-positive neurons in these rats as well as in those receiving a lower dose $(0.05 \mathrm{mg} / \mathrm{kg}$, s.c.) of DEX for 1 week or a single injection of DEX $(0.5 \mathrm{mg} / \mathrm{kg}$, s.c.; acute). The number of ChAT-positive neurons in control rats was $31.6 \pm 1$ per section. Values, expressed as percent of control, are the mean \pm SEM of three separate experiments with at least three animals per group in each experiment. ${ }^{*} p<0.05$, and ${ }^{*} p<0.005$ (ANOVA and Fisher's test).

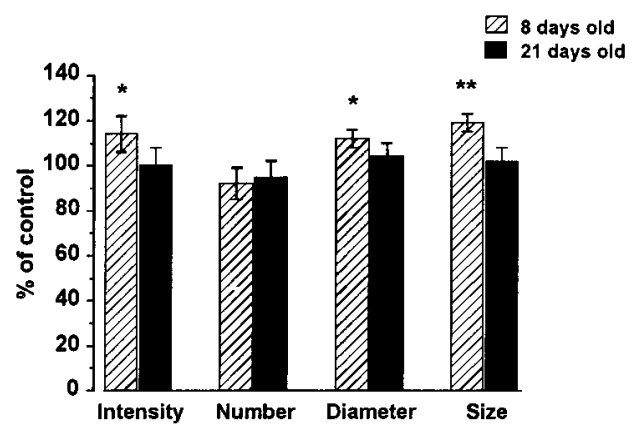

Figure 4. Age-dependent changes in the morphology of ChATimmunoreactive neurons. P1 and P14 rats were treated with vehicle or DEX for 1 week and killed $8 \mathrm{hr}$ after the last injection. Various morphological parameters of cholinergic neurons of the medial septum were evaluated as described in Figure 3. Values, expressed as percent of control, are the mean \pm SEM of three separate experiments with two rats per group in each experiment. ${ }^{*} p<0.05$, and ${ }^{* *} p<0.005$ (ANOVA and Fisher's test).

\section{DEX fails to change NGF and p75NTR mRNA and ChAT immunoreactivity in the spinal cord}

NGF is a trophic factor for cholinergic neurons of the basal forebrain and striatum but not for cholinergic motor neurons of the spinal cord (Yan et al., 1988). Thus, the spinal cord is an ideal area of the CNS in which to strengthen or eliminate the possibility that DEX increases ChAT levels and p75NTR via its effect on NGF synthesis. P7 rats received DEX $(0.5 \mathrm{mg} / \mathrm{kg}$, s.c. $)$ for $7 \mathrm{~d}$ and were killed 6 and $8 \mathrm{hr}$ after the last injection for the determination of NGF and p75NTR mRNAs and of ChAT immunoreactivity, respectively. DEX failed to increase NGF and p75NTR mRNAs (Fig. 8) as well as ChAT immunoreactivity (Fig. 9). Taken to-

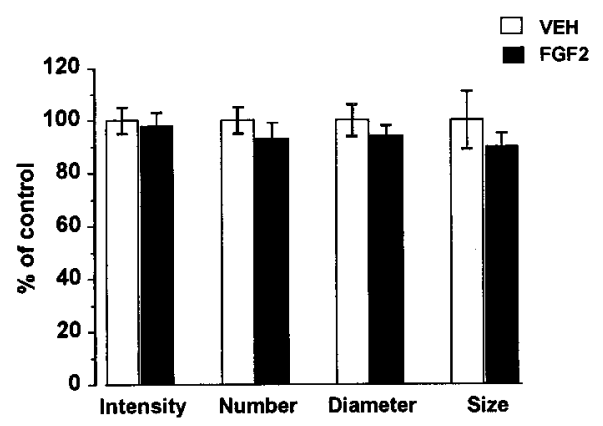

Figure 5. Effect of FGF2 on ChAT-immunoreactive neurons in the medial septum. Pups at P7 were removed from their mothers, anesthetized with chloral hydrate, and fixed in a plaster mold of the head and body. Either artificial CSF (ACSF; $V E H$ ) or FGF2 dissolved in ACSF at a concentration of $6 \mu \mathrm{g} / 10 \mu \mathrm{l}$ was injected, at a rate of $1 \mu \mathrm{g} / \mathrm{min}$, into the right cerebral ventricle according to the following coordinates: $0.2 \mathrm{~mm}$ posterior to bregma, $1.5 \mathrm{~mm}$ lateral to midline, and $2.4 \mathrm{~mm}$ to the dural surface (Kirschner et al., 1995). After $3 \mathrm{hr}$ of recovery, the pups were returned to their dam. Injections were done at P7, P9, P11, and P13. Animals were killed at P14, and brains were processed for the analysis of the various morphological parameters of cholinergic neurons as described in Figure 3.

gether, our data suggest that the differential trophic activity of DEX on basal forebrain cholinergic neurons seems to be linked to its ability to increase NGF synthesis.

\section{DISCUSSION}

Previous studies have demonstrated that glucocorticoids, but not mineral corticoids, are the main corticosteroids regulating the expression of NGF in the rat brain (Mocchetti et al., 1996). We have hypothesized that this increase has a physiological implica- 

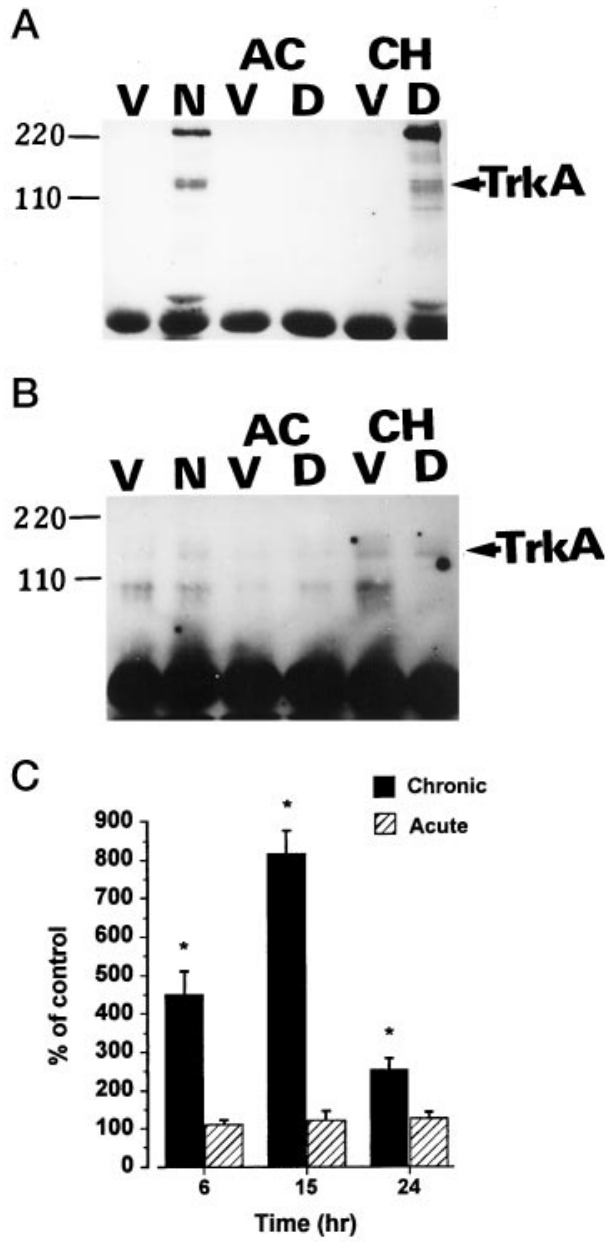

Figure 6. DEX induces TrkA phosphorylation in the septum. Seven-dayold rats received a single or chronic (7 d) injection of vehicle or DEX and were killed 6,15 , or $24 \mathrm{hr}$ after the last injection. Fourteen-day-old rats received vehicle or NGF (30 $\mu \mathrm{g}$ of $\mathrm{NGF} / 10 \mu \mathrm{l}$ of vehicle, i.c.v.) and were killed $1 \mathrm{hr}$ later. The septi from two rats were combined for the analysis of TrkA tyrosine phosphorylation using a specific TrkA antibody (Clary et al., 1994). $A$, Representative blot showing an increase in TrkA tyrosine phosphorylation (arrow) in 1 week $(C H)$ DEX-treated rats $(D)$ compared with vehicle-treated rats $(V)$ and with rats receiving a single acute injection and killed $15 \mathrm{hr}$ later $(A C)$. Lysates from artificial CSF-treated $(V)$ or NGF-treated $(N)$ rats were used as a positive control. $B$, Blot stripped and reprobed with pan-trk antibody. The arrow indicates levels of TrkA. Molecular weight markers are indicated on the left. $C$, Semiquantitative analysis of the TrkA-phosphorylated species performed by scanning the TrkA band with a laser densitometer. Data are the mean \pm SEM of three independent and separate experiments with four rats per group in each experiment. ${ }^{*} p<0.001$ versus control (ANOVA and Dunnett's test).

tion for neuronal plasticity based on the well-established role of NGF in promoting the development of basal forebrain cholinergic neurons in vivo (Gnahn et al., 1983; Mobley et al., 1986; Vantini et al., 1989; Li et al., 1995). We show that, in P8 and P14 rats, a subchronic treatment with DEX leads to a prolonged increase in NGF mRNA and protein (suggestive of increased synthesis) in the hippocampus and cerebral cortex and causes hypertrophy of cholinergic neurons in the medial septum. However, in P21 rats, DEX failed to change NGF levels and did not alter the postnatal development of these cholinergic neurons. Thus, our data provide a correlation between induction of NGF by DEX and increased cholinergic plasticity. In addition, other experimental groups
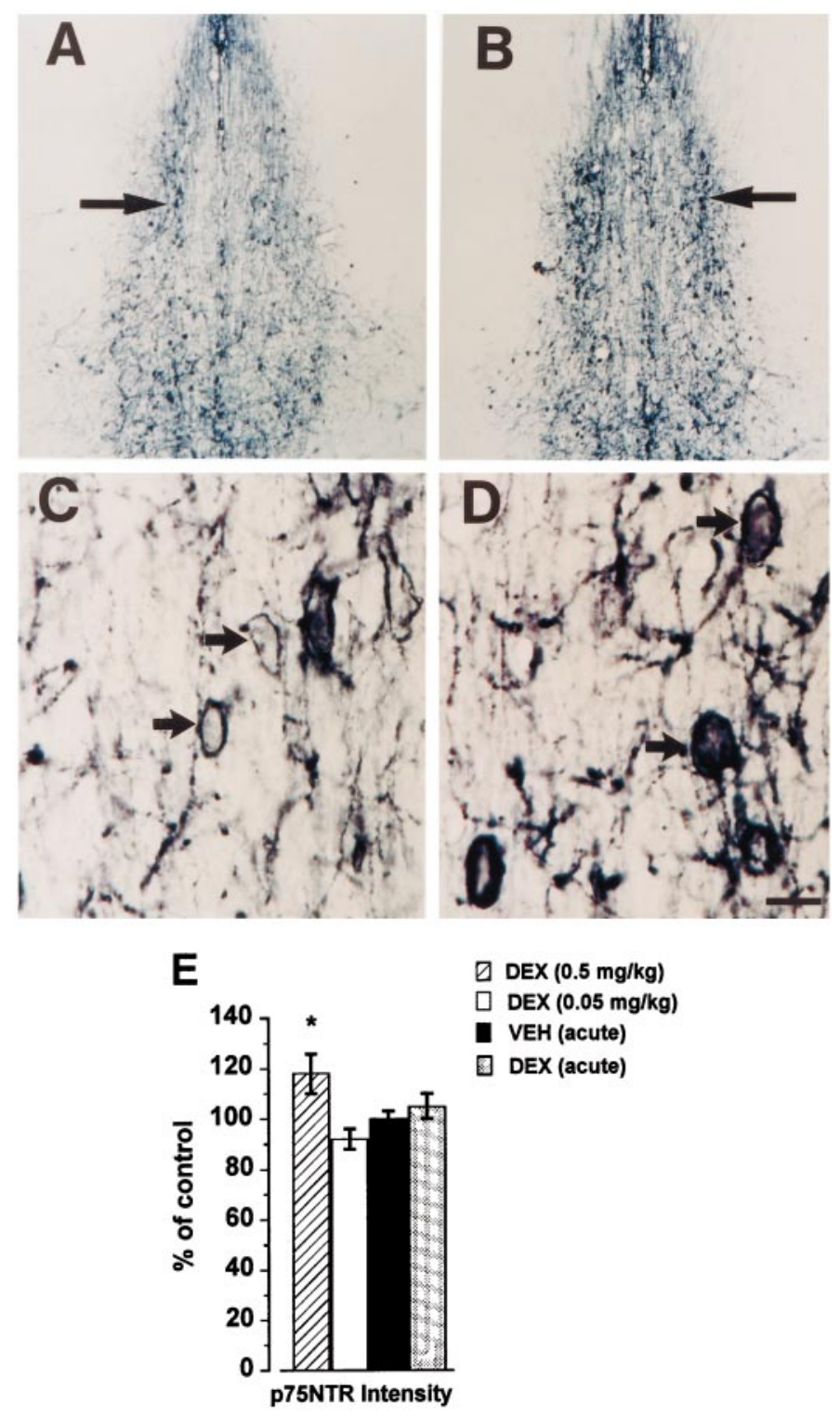

Figure 7. Effect of DEX on p75NTR immunoreactivity. Fourteen-dayold rats received vehicle or DEX for $7 \mathrm{~d}$ and were killed $8 \mathrm{hr}$ after the last injection. $A-D$, p75NTR immunoreactivity analyzed in the medial septum. $C$ and $D$ are higher magnifications of areas indicated by arrows in $A$ and $B$, respectively. There was more immunoreactive staining in cell bodies (arrows) in DEX-treated rats $(D)$ than in cell bodies in controls $(C$, arrows). Scale bars: $A, B, 250 \mu \mathrm{m} ; C, D, 20 \mu \mathrm{m}$. $E$, Quantitation by image analysis of p75NTR immunoreactivity in the septum. Data are the mean \pm SEM of two separate experiments with three rats per group in each experiment. ${ }^{*} p<0.005$ (ANOVA and Fisher's test).

were used to provide a causal relationship between the trophic activity of DEX and its ability to increase NGF. The DEXmediated cholinergic hypertrophy was seen only at a dose $(0.5$ $\mathrm{mg} / \mathrm{kg}$ ) and time (1 week treatment) at which DEX upregulates NGF synthesis in the hippocampus and cerebral cortex. In fact, a lower but repeated dose $(0.05 \mathrm{mg} / \mathrm{kg}$ for $7 \mathrm{~d})$ or a single injection was unable to change the levels of ChAT immunoreactivity. Furthermore, DEX failed to change ChAT immunoreactivity in the spinal cord, a non-NGF-responsive CNS structure (Yan et al., 1988), in which we did not see a significant change in NGF biosynthesis. Overall, these data suggest that DEX induces an age-dependent differential hypertrophy of medial septal cholin- 


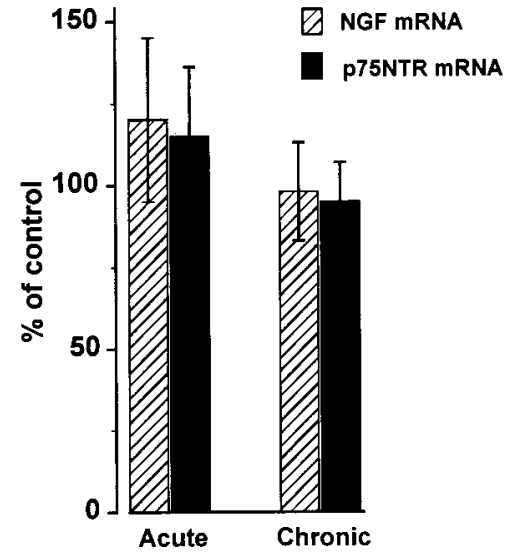

Figure 8. NGF and p75NTR mRNA levels are not induced by DEX in the spinal cord. Seven-day-old rats received vehicle or DEX $(0.5 \mathrm{mg} / \mathrm{kg}$, s.c.) acutely or for $7 \mathrm{~d}$ and were killed $6 \mathrm{hr}$ after the last injection. Spinal cords were removed and dissected to obtain the cervical segment for RNA analysis. NGF and p75NTR mRNA levels were analyzed by RNase protection assay as described previously. Data are the mean \pm SEM of two separate experiments with three independent samples in each experiment.

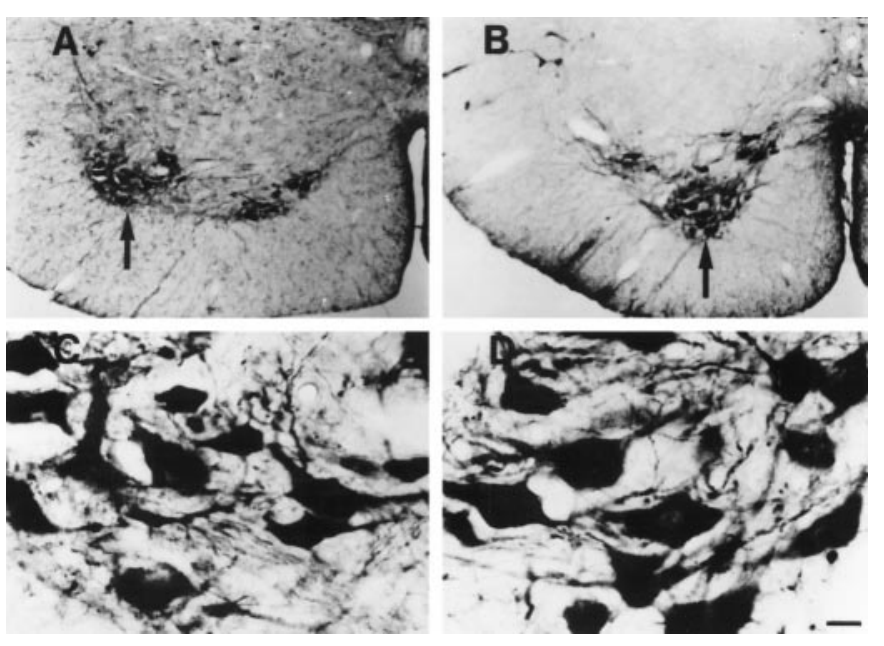

Figure 9. DEX fails to change ChAT immunoreactivity in the spinal cord. $A, B, \mathrm{P} 7$ rats were treated with vehicle $(A)$ or DEX $(B)$ for $7 \mathrm{~d}$. ChAT immunoreactivity was analyzed in the spinal cord (cervical segment). $C, D$, Higher magnifications of areas indicated by arrows in $A$ and $B$, respectively, are shown. There was no difference in the levels of ChAT immunoreactivity between DEX- and vehicle-treated rats. Scale bars: $A$, $B, 100 \mu \mathrm{m} ; C, D, 10 \mu \mathrm{m}$.

ergic neurons and that this trophic effect may be attributable to its ability to increase NGF availability.

Most of the trophic effects of NGF require activation of the TrkA receptor. It has been established that NGF binding to TrkA evokes a highly specific, rapid, and easily measurable receptor autophosphorylation (Kaplan et al., 1991). Thus, phosphorylation of TrkA can be a useful response to estimate downstream biological effectiveness of NGF. Our data show that the subchronic treatment with DEX increases TrkA tyrosine phosphorylation in the septum. The increase in TrkA tyrosine phosphorylation by DEX was specific because no changes were seen in TrkA phosphorylation after a single injection of DEX or in the hippocampus, suggesting that the effect of DEX is selective and may not be related to a generalized induction of tyrosine phosphorylation. In addition, we have observed multiple phosphotyrosine-positive bands in phosphotyrosine blots of lysates immunoprecipitated with TrkA antibody. The presence of these bands is not surprising and most probably is caused by the association of tyrosinephosphorylated TrkA target proteins with the immunoprecipitated receptor (Hempstead et al., 1992). Because TrkA activation leads to a measurable increase in the phosphorylation of phospholipase $\mathrm{C}-\gamma$ and several other cellular proteins identified as targets of NGF-induced TrkA tyrosine phosphorylation (for review, see Kaplan and Stevens, 1994), the presence of these bands is quite supportive of the activation of TrkA after DEX treatment.

NGF binds also to a low-affinity receptor component, an $\sim 75$ kDa cell surface glycoprotein (Chao et al., 1986; Radeke et al., 1987) designated p75NTR. Most cholinergic neurons in the basal forebrain are both TrkA- and p75NTR-positive (Koh et al., 1989; Pioro and Cuello, 1990; Holtzman et al., 1992; Sobreviela et al., 1994), and p75NTR has also been used as an early cholinergic marker expressed during development (Yan and Johnson, 1988; Koh and Loy, 1989). Moreover, it has been established that high levels of NGF can increase the expression of p75NTR both in vivo (Higgins et al., 1989) and in vitro (Kojima et al., 1992; Meakin et al., 1992; Colangelo et al., 1994), whereas reduced levels of NGF by an anti-NGF antibody decreased p75NTR levels in the basal forebrain (Urschel and Hulsebosh, 1992), suggesting that p75NTR expression correlates with increases in NGF levels and cholinergic neuronal development. Therefore, in our studies we used 75NTR immunoreactivity as an additional tool to analyze NGF responses and to correlate them with the DEX-mediated enhanced plasticity of cholinergic neurons in the medial septum. Our data show that DEX elicited an upregulation of p75NTR immunoreactivity in the medial septum, a typical NGF target, but not in the spinal cord, an NGF-unresponsive area of the CNS in which we failed to detect increases in NGF expression. Thus, by showing that two NGF-responsive genes, ChAT and p75NTR, are induced by DEX only in their target areas in which NGF levels are upregulated, we provide further evidence of the hypothesis that the trophic activity of DEX depends on its ability to increase NGF biosynthesis.

Cholinergic neurons of the basal forebrain of the rat innervate the hippocampal formation, the cingulate cortex, the olfactory bulb, and some additional structures (Mesulam et al., 1983; Cuello and Sofroniew, 1984; Butcher, 1995). NGF, produced in these structures, after binding to the NGF receptor complex, can be retrogradely transported to the basal forebrain cell bodies to activate the expression of specific proteins. In particular, a retrograde transport of NGF from the hippocampal formation and cortex to cholinergic neurons of the medial septum and the nucleus basalis, respectively, has been demonstrated (Schwab et al., 1979; Seiler and Schwab, 1984; DiStefano et al., 1992). In these brain areas, NGF modulates the plasticity of cholinergic neurons by increasing their number, size, and connections (Garofalo et al., 1992; Koliatsos et al., 1994; Fagan et al., 1997b). In this report, we observed an increase in NGF levels in both the hippocampus and the cerebral cortex after DEX, suggesting that this glucocorticoid may affect cholinergic neurons in both the medial septum and the nucleus basalis. Previous results, however, have shown that DEX increases NGF expression in the dentate gyrus of the hippocampus (Mocchetti et al., 1996) and in layers II and III of the cerebral cortex (Mocchetti et al., 1996). Although the dentate gyrus of the hippocampus receives cholinergic projections from the medial septum via septohippocampal efferents 
(Mesulam et al., 1983; Cuello and Sofroniew, 1984; Butcher, 1995), layers II and III of the cortex contain predominantly corticocortical projections. Thus, the DEX-induced cortical NGF may not be transported retrogradely to the basal forebrain. Therefore, we have first focused our effort on the effect of DEX on the cholinergic neurons of the medial septum. We have found that DEX increases the relative number and size of the cholinergic neurons in the medial septum. This effect occurs concomitantly with an increase in p75NTR and TrkA tyrosine phosphorylation in the septum and in NGF levels in the hippocampus, consistent with the hypothesis that the main trophic effect and source of DEX is the hippocampal NGF. Future studies will establish whether cortical-induced NGF exerts a trophic activity on cholinergic neurons of the nucleus basalis.

DEX increases the relative cell density of septal cholinergic neurons at P14 without affecting their size. Thus, as for the exogenous NGF, higher levels of endogenously produced NGF appear to be sufficient to affect the number of septal cholinergic neurons during postnatal development. In support of this hypothesis, we have demonstrated that the net increase in TrkA phosphorylation in DEX-treated animals was comparable with that observed in NGF-treated rats, suggesting that the endogenously produced NGF has a potency and perhaps biological activity similar to that of the exogenously administered NGF. On the other hand, the increased density of cholinergic neurons observed in our study may only reflect an increase in ChAT immunoreactivity in those neurons that, in basal conditions, express low or undetectable levels of the enzyme. Future studies using a quantitative analysis by unbiased stereological methods (Peterson et al., 1997; Yeo et al., 1997) and a biochemical determination of ChAT will confirm whether DEX increases the number of cholinergic neurons or ChAT activity, respectively.

In conclusion, our data have shown that a prolonged treatment with DEX causes cholinergic neuron hypertrophy during the early development. This effect correlates with a defined regional pattern of induction of NGF expression as well as responses typically associated with high levels of NGF. Thus, our data suggest that glucocorticoids, by increasing NGF availability and perhaps synthesis, possess trophic activity. This effect may explain the findings that physiological concentrations of glucocorticoids are crucial for neuronal survival because adrenalectomy accelerates degeneration of hippocampal neurons (Sloviter et al., 1989, 1993), ACTH regulates trophic processes operative in synaptic plasticity (Strand et al., 1989), and DEX enhances survival and maturation of cholinergic neurons during development (Puro, 1983; Sze et al., 1993; Zahalka et al., 1993). Our studies so far have focused on the effect of DEX on cholinergic neurons during development. The extent by which DEX can restore basal forebrain cholinergic function in adult injured neurons or in aged rats in which the plasticity of cholinergic neurons is impaired (Decker, 1987; Cooper and Sofroniew, 1996) needs to be assessed in future studies.

\section{REFERENCES}

Abercrombie M (1946) Estimation of nuclear population from microtome sections. Anat Rec 94:239-247.

Aloe L (1989) Adrenalectomy decreases nerve growth factor in young adult rat hippocampus. Proc Natl Acad Sci USA 86:5636-5640.

Anderson KJ, Dam D, Lee S, Cotman CW (1988) Basic fibroblast growth factor prevents death of lesioned cholinergic neurons in vivo. Nature 332:360-361.

Barbany G, Persson H (1992) Regulation of neurotrophin mRNA expression in the rat brain by glucocorticoids. Eur J Neurosci 4:396-403.
Butcher LL (1995) Cholinergic neurons and networks. In: The rat nervous system, Second Edition (Paxinos G, ed), pp 1003-1013. San Diego: Academic.

Chao MV, Bothwell MA, Ross AH, Koprowski H, Lanahan A, Buck CR, Sehgal A (1986) Gene transfer and molecular cloning of the human NGF receptor. Science 232:418-421.

Clary DO, Weskamp G, Austin LA, Reichardt LF (1994) TrkA crosslinking mimics neuronal responses to nerve growth factor. Mol Biol Cell 5:549-563.

Colangelo AM, Fink DW, Rabin SJ, Mocchetti I (1994) Induction of nerve grow th factor responsiveness in C6-2B glioma cells by expression of trkA proto-oncogene. Glia 12:117-127.

Colangelo AM, Follesa P, Mocchetti I (1998) Differential induction of nerve growth factor and basic fibroblast growth factor mRNA in neonatal and aged rat brain. Mol Brain Res 53:218-225.

Cooper JD, Sofroniew MV (1996) Increased vulnerability of septal cholinergic neurons to partial loss of target neurons in aged rats. Neuroscience 75:29-35.

Coyle JT, Price DL, DeLong MR (1983) Alzheimer's disease: a disorder of cortical cholinergic innervation. Science 219:1184-1190.

Cuello AC, Sofroniew MV (1984) The anatomy of the CNS cholinergic neurons. Trends Neurosci 7:74-78.

Decker MW (1987) The effects of aging on hippocampal and cortical projections of the forebrain cholinergic system. Brain Res Rev 12:423-438.

DiStefano PS, Friedman B, Radziejewski C, Alexander C, Boland P, Schick CM, Lindsay RM, Wiegand SJ (1992) The neurotrophins BDNF, NT-3 and NGF display distinct patterns of retrograde axonal transport in peripheral and central nervous neurons. Neuron 8:983-993.

Fabrazzo M, Costa E, Mocchetti I (1991) Reserpine stimulates nerve growth factor biosynthesis in developing rat brain: steroids as possible mediators. Mol Pharmacol 39:144-149.

Fagan AM, Suhr ST, Lucidi-Phillipi CA, Peterson DA, Holtzman DM, Gage FH (1997a) Endogenous FGF-2 is important for cholinergic sprouting in the denervated hippocampus. J Neurosci 17:2499-2511.

Fagan AM, Garber M, Barbacid M, Silos-Santiago I, Holtzman DM (1997b) A role of trkA during maturation of striatal and basal forebrain cholinergic neurons in vivo. J Neurosci 17:7644-7654.

Fisher W, Wictorin K, Bjorklund A, Williams LR, Varon S, Gage FH (1987) Amelioration of cholinergic neuron atrophy and spatial memory impairment in aged rats by nerve growth factor. Nature 329:65-68.

Follesa P, Gale K, Mocchetti I (1994) Regional and temporal pattern of expression of nerve growth factor and basic fibroblast growth factor mRNA in rat brain following electroconvulsive shock. Exp Neurol 127:37-44.

Garofalo L, Riberio Da Silva A, Cuello C (1992) Nerve growth factorinduced synaptogenesis and hypertrophy of cortical cholinergic terminals. Proc Natl Acad Sci USA 89:2639-2643.

Glowinski J, Iversen LL (1966) Regional distribution of catecholamines in rat brain. I. The disposition of ${ }^{3} \mathrm{H}$-norepinephrine: dopamine and DOPA in various regions of the brain. J Neurochem 13:655-669.

Gnahn H, Hefti F, Heumann R, Schwab ME, Thoenen H (1983) NGFmediated increase of choline acetyltransferase (ChAT) in the neonatal rat forebrain: evidence for a physiological role of NGF in the brain. Dev Brain Res 9:42-52.

Gould E, Woolf NJ, Butcher LL (1991) Postnatal development of cholinergic neurons in the rat. I. Forebrain. Brain Res Bull 27:767-789.

Hayes VY, Isackson PJ, Fabrazzo M, Follesa P, Mocchetti I (1995) Induction of nerve growth factor and basic fibroblast growth factor mRNA following clenbuterol: contrasting anatomical and cellular localization. Exp Neurol 132:33-41.

Hempstead BL, Rabin ST, Kaplan L, Reid S, Parada LF, Kaplan DR (1992) Overexpression of the trk tyrosine kinase rapidly accelerates nerve growth factor induced differentiation. Neuron 9:883-896.

Higgins GA, Koh S, Chen KS, Gage H (1989) NGF induction of NGF receptor gene expression and cholinergic neuronal hypertrophy within the basal forebrain of the adult rat. Neuron 3:247-256.

Holtzman DM, Li Y, Parada LF, Kinsman S, Chen C-K, Valletta JS, Zhou J, Long JB, Mobley W (1992) p140 ${ }^{\text {trk }}$ mRNA marks NGFresponsive forebrain neurons: evidence that trk gene expression is induced by NGF. Neuron 9:465-478.

Kaplan DR, Stevens RM (1994) Neurotrophin signal transduction by the trk receptor. J Neurobiol 25:1404-1417.

Kaplan DR, Hempstead BL, Martin-Zanca D, Chao MV, Parada LF 
(1991) The trk protooncogene product: a signal transducing receptor for nerve growth factor. Science 252:554-558.

Kirschner PB, Henshaw R, Weise J, Trubetskoy V, Finklestein S, Schulz JB, Beal MF (1995) Basic fibroblast growth factor protects against excitotoxicity and chemical hypoxia in both neonatal and adult rats. J Cereb Blood Flow Metab 15:619-623.

Koh S, Loy R (1989) Localization and development of nerve growth factor-sensitive rat basal forebrain neurons and their afferent projection to hippocampus and neocortex. J Neurosci 9:2999-3018.

Koh S, Oyler GA, Higgins GA (1989) Localization of nerve growth factor receptor mRNA and protein in the adult rat brain. Exp Neurol 106:209-221.

Kojima M, Takahashi N, Ikeuchi T, Hatanaka H (1992) Nerve growth factor mediated up-regulation of low-affinity NGF receptor gene expression in cultured basal forebrain cholinergic neurons from postnatal 3-day-old rats. Mol Brain Res 16:267-273.

Koliatsos VE, Price DL, Gouras GK, Cayouette M, Burton LE, Winslow JW (1994) Highly selective effects of nerve growth factor, brain derived neurotrophic factor and neurotrophin-3 on intact and injured basal forebrain magnocellular neurons. J Comp Neurol 343:247-262.

Korsching S, Thoenen H (1985) Treatment with 6-hydroxydopamine and colchicine decreases nerve growth factor levels in sympathetic ganglia and increases them in the corresponding target tissues. J Neurosci 5:1058-1061.

Li Y, Holtzman DM, Kromer LF, Kaplan DR, Chua-Couzens J, Clary DO, Knüsel B, Mobley WC (1995) Regulation of TrkA and ChAT expression in developing rat basal forebrain: evidence that both exogenous and endogenous NGF regulate differentiation of cholinergic neurons. J Neurosci 15:2888-2905.

McEwen B, De Kloet ER, Rostene W (1986) Adrenal steroid receptors and action in the nervous system. Physiol Rev 66:1121-1188.

Meakin SO, Suter U, Drinkwater CC, Welcher AA, Shooter EM (1992) The rat trk protooncogene product exhibits properties characteristic of the slow nerve growth factor receptor. Proc Natl Acad Sci USA 89:2374-2378.

Mesulam MM, Mufson EJ, Wainer BH, Levey AI (1983) Central cholinergic pathways in the rat: an overview based on alternative nomenclature (Ch1-Ch6). Neuroscience 10:1185-1201.

Mobley WC, Rutkowski C, Tennenkoon JL, Gemski I, Buchanan K, Johnston MV (1986) Nerve growth factor increases choline acetyltransferase activity in developing basal forebrain neurons. Mol Brain Res 1:53-62.

Mocchetti I, Spiga G, Hayes VY, Isackson PJ, Colangelo AM (1996) Glucocorticoids differentially increase nerve growth factor and basic fibroblast growth factor expression in the rat brain. $J$ Neurosci 16:2141-2148.

Peterson DA, Leppert JT, Lee K-F, Gage FH (1997) Basal forebrain neuronal loss in mice lacking neurotrophic receptor p75. Science 277:837-839.

Pioro EP, Cuello CA (1990) Distribution of nerve growth factor receptor-like immunoreactivity in the adult rat central nervous system: effect of colchicine and correlation with the cholinergic system. Neuroscience 34:57-87.

Puro DG (1983) Glucocorticoid regulation of synaptic development. Brain Res 283:283-290.

Rabin SJ, Mocchetti I (1995) GM1 ganglioside activates the high affinity nerve growth factor receptor trkA. J Neurochem 65:1-8.

Radeke MJ, Misko TP, Hsu C, Herenberg LA, Schooter EM (1987) Gene transfer and molecular cloning of the rat nerve growth factor receptor. Nature 325:593-597.

Saporito MS, Brown ER, Hartpence KC, Heide MW, Robbins E, Vaught J, Carswell S (1994) Systemic dexamethasone administration increases septal trk autophosphorylation in adult rats via an induction of nerve growth factor. Mol Pharmacol 45:395-401.
Schwab ME, Otten U, Agid Y, Thoenen H (1979) Nerve growth factor (NGF) in the rat CNS: absence of specific retrograde axonal transport and tyrosine hydroxylase induction in locus coeruleus and substantia nigra. Brain Res 168:473-483.

Seiler M, Schwab ME (1984) Specific retrograde transport of nerve growth factor from neocortex to nucleus basalis in the rat. Brain Res 300:33-39.

Shimasaki S, Emoto N, Koba A, Mercado M, Shibata F, Cooksey K, Baird A, Ling N (1988) Complementary DNA cloning and sequencing of rat ovarian basic FGF and tissue distribution study of its mRNA. Biochem Biophys Res Commun 157:256-263.

Sloviter RS, Valiquette G, Abrams GM, Ronk EC, Sollar AL, Paul Lam, Neubort S (1989) Selective loss of hippocampal granule cells in the mature rat brain after adrenalectomy. Science 243:1432-1437.

Sloviter RS, Sollas AL, Dean E, Neubort S (1993) Adrenalectomyinduced granule cell degeneration in the rat hippocampal dentate gyrus: characterization of an in vivo model of controlled neuronal death. J Comp Neurol 330:324-336.

Sobreviela T, Clary DO, Reichardt LF, Brandabur MM, Kordower JH, Mufson EJ (1994) TrkA-immunoreactive profiles in the central nervous system: p75 nerve growth factor receptor, choline acetyltransferase, and serotonin. J Comp Neurol 350:587-611.

Sofroniew MV, Cooper JD, Svendsen CN, Crossman P, Ip NY, Lindsay RM, Zafra F, Lindholm D (1993) Atrophy but not death of adult septal cholinergic neurons after ablation of target capacity to produce mRNAs for NGF, BDNF, and NT3. J Neurosci 13:5263-5276.

Strand FL, Rose KJ, King JA, Segarra AC, Zuccarelli LA (1989) ACTH modulation of nerve development and regeneration. Prog Neurobiol 33:45-85.

Sun F-Y, Costa E, Mocchetti I (1993) Adrenal steroids mediate the increase of hippocampal nerve growth factor biosynthesis following bicuculline convulsions. Neuropsychopharmacology 8:219-225.

Sze PY, Marchi M, Towley AC, Giacobini E (1993) Increased uptake of ${ }^{3}[\mathrm{H}]$ choline by rat superior cervical ganglia: an effect by dexamethasone. Neuropharmacology 22:711-716.

Teng YD, Mocchetti I, Wrathall JR (1998) Basic and acidic fibroblast grow th factors protect spinal motor neurones in vivo after experimental spinal cord injury. Eur J Neurosci 10:798-802.

Urschel BA, Hulsebosh CE (1992) Distribution and relative density of p75 nerve growth factor receptors in the rat brain as a function of age and treatment with antibodies to nerve growth factor. Brain Res 591:223-238.

Vantini G, Schiavo N, DiMartino A, Polato P, Triban C, Callegaro L, Toffano G, Leon A (1989) Evidence for a physiological role of NGF in the central nervous system of neonatal rats. Neuron 3:267-273.

Whittemore SR, Friedman PL, Larhammar D, Persson H, GonzalesCarvajal M, Holets VR (1988) Rat $\beta$-nerve growth factor sequence and site of synthesis in the adult hippocampus. J Neurosci Res 20:403-410.

Yan Q, Johnson EM (1988) An immunohistochemical study of the nerve growth factor receptor in developing rats. J Neurosci 8:3481-3498.

Yan Q, Snider WD, Pinzone JJ, Johnson EM (1988) Retrograde transport of nerve growth factor in motoneurons of developing rats: assessment of potential neurotrophic effects. Neuron 1:335-343.

Yeo TT, Chua-Couzen J, Butcher LL, Bredeson DE, Cooper JD, Vallette JS, Mobley WC, Longo FM (1997) Absence of p75NTR causes increased basal forebrain cholinergic neuron size, choline acetyltransferase activity, and target innervation. J Neurosci 17:7594-7605.

Zahalka EA, Sedler FJ, Slotkin TA (1993) Dexamethasone treatment in utero enhances neonatal cholinergic nerve terminal development in rat brain. Res Commun Chem Pathol Pharmacol 81:191-198. 